denuded and stitched together by interrupted silkwormgut sutures.

An opening made through the wall of the uterus into the uterine cavity at a point corresponding with the location of the external meatus and a retention catheter inserted up through the dilated cervical canal into the bladder.

The parts are approximated with sufficient firmness to prevent leakage from the now fully-constructed bladder. The vagina is loosely packed with iodoform gauze and the patient put to bed. Permanent drainage is established by means of the catheter and extension tubing leading into a receptable containing a 1-2000 bichlorid solution.

The newly-formed bladder is washed out with a saturated solution of boric acid every eight hours and the external parts bathed with the bichlorid solution, followed with sterile water and dusted with aristol or some antiseptic powder.*

OTHER METHODS IMPRACTICABLE.

When we consider the horrible state the patient is in, the danger of infection extending to ureters and kidneys, the depressing mental effect, the impairment of general health, the danger to life, some radical procedure for relief seems imperative. Again, the usual methods will not suffice. Entire closure, whether or not it includes the vagina, as in urinary fistulæ, makes no provision for voluntary urination. A suprapubic opening as used in the male would be inapplicable. The gradual drawing downward of the uterus until it can be used for plastic closure of the bladder opening could not be done in this case, owing to the adhesions and fixation. Rolling up of vaginal tissue to form a urethra after the unique method of MacArthur and subsequently using the device of Kolesche, so ingeniously perfected by Fletcher, for controlling the flow of urine, was not possible because scarcely any anterior vaginal wall tissue was available. The transplantation of the trigone into the rectum was contraindicated by the insufficiency of the rectal sphincter. Indeed, all known methods seemed impracticable.

\section{ADVANTAGES AND DISADVANTAGES.}

The method proposed has in its favor these points. The entire operation for closing the bladder and furnishing a urinary tract can be done at one sitting, with a strong probability of its successful issue. The saving of time and suffering to the patient is a great consideration.

The possible sources of failure might be: insufficient collateral circulation in the uterus separated from its posterior attachments. The use of serous instead of mucous membrane for the bladder floor might be more or less objectionable, though this has already been successfully reported; the uncertainty of inducing sphincter-like control of the circular fibers of the cervix uteri.

In spite of these difficulties I believe it is possible to use as a factor in forming another urethra the hyperinvolute, deformed uterus which has now no functional value proportionate to the service it might be made to perform.

100 State Street.

* This operation should not be confounded with the simple drawing down of the uterus without inversion for plastic work. nor
with Freund's procedure in cases of vesical and rectal fistulæ. In with Freund's procedure in cases of vesical and rectal fistulæ. In
this latter only the body of the uterus is used, the cervix above being curled on itself and walled off by cicatricial tissue.

Treatment of Warts.-Kaposi used to advise painting the wart and adjacent tissues every day with a mixture of bichlorid one part to thirty parts collodion.

\section{OBSERVATIONS ON SOME RECENT CASES OF ORTHODONTIA.*}

\section{E. A. BOGUE, M.D.}

NEW YORK CITY.

The two cases that I have been observing are brother and sister, eight and nine years old, respectively, and the observations have continued for a little more than two years. Both these children presented the curious anomaly of irregular deciduous teeth, though the teeth of both parents were, until extractions were practiced, remarkably regular. This irregularity of the temporary teeth meant, of course, contracted arches. In the case of the boy the contraction was so great that the lips fell

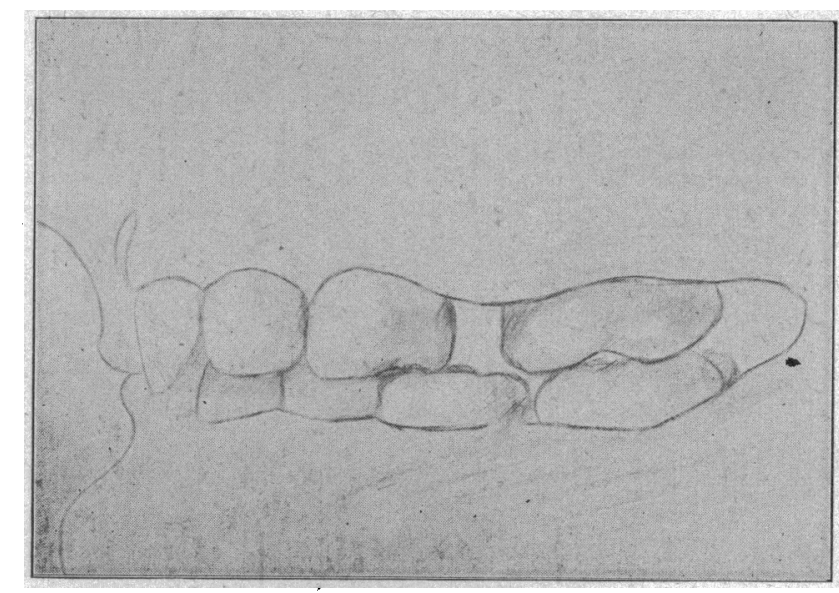

Fig. 1.-John M., 8 years old. Teeth closed and upper molar far in advance of its proper position. Lips fallen in like an old edentulous person.

in like those of an edentulous person (see cut of profile), giving him the appearance of a very old man. I greatly regret that I did not have a photographic profile made at the time, but his mother was so confident that she had one that I did not urge the matter, and it is now too late to secure this almost unique specimen.

The problem in both cases was to procure an enlargement of both arches in the easiest and most painless way

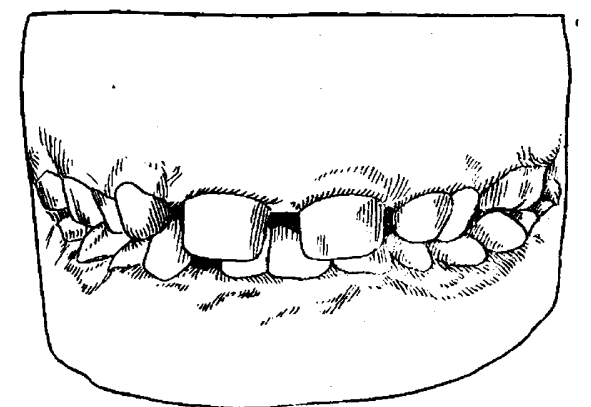

Fig. 1A.-John M., 8 years old. Mouth as it was July, 1899, closed.

possible, and with the least detriment to the teeth and disturbance to the children, and then to retain these teeth in their new positions, holding them out of one another's way during the continued shedding of the temporary teeth and the eruption of the permanent ones.

As children of that age are constantly active, fingers, tongue and lips included. I determined upon fixed, that is to say, nonremovable apparatus, and the first was put on April 19, 1900, when the boy was just eight years old and the girl about nine.

* Read at the Fifty-third Annual Meeting of the American Medical Association. in the Section on Stomatology and approved for publication by the Executive Committee : Drs. G. V. I. Brown,
H. Fletcher and R. R. Andrews. 
The fixtures consisted of gold tubes, soldered to rings, which were cemented on to the molar teeth; a wire screw bow carrying nuts at each end, the bows passing around in front of the incisors to which they were attached by loops soldered to rings fitted over and cemented to the incisors, the ends of the bows being passed into the tubes on the molars. The position of the nuts on the ends of the bows was in front of the tubes. It will be perceived therefore that ligatures of any kind could be attached to any or all of the intervening teeth between the molars and the central incisors, which were

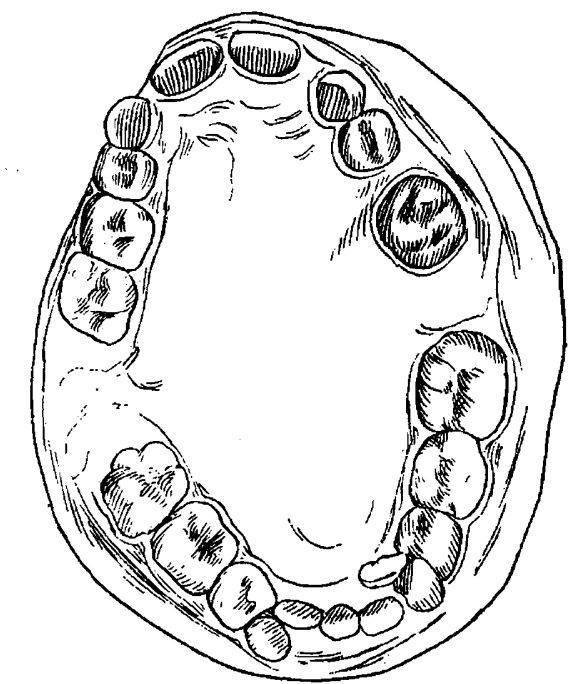

Fig. 1B.-John M., 8 years old. Mouth as it was July, 1899, open the points of permanent attachment. The reason for putting two nuts on each end of these wire bows is that one nut may serve as a jam nut to keep the other from turning backward after the pressure arising from its work has been relieved by the movement desired. In the case of the boy the upper incisors were so far within the arch as to make the child seem, as before stated, edentulous. Expansion was therefore begun on the upper jaw by turning the nuts on the wire bow a day

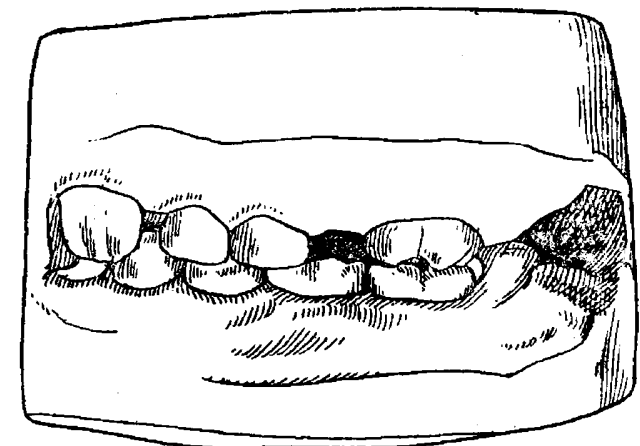

Fig. 1C.-John M., July, 1899 . Shows teeth closed and the upper molar far in advance of its proper position.

or two after the rings had been cemented into place, the bow inserted into the tubes and the patient had become accustomed to the apparatus being in place. About two weeks later a similar fixture was adapted to the lower teeth, this bow being attached to the two lateral incisors, this time by means of grass-line ligatures. Pressure was applied in both cases by turning the nuts and renewing the grass-line ligatures, and in forty days such progress was made as rendered it quite safe for the boy to go away. He sailed for Europe June 6, 1900, with the regulating fixtures in place. One or two of the rings attached to the incisors came off and had to be recemented during his absence, but this was easily accom- plished, and he returned from Europe and was presented for observation November 16. He had been absent five months and ten days with very slight attention to the fixtures during that time.

In December a gold wire retaining fixture was inserted to keep the lower incisors forward, where they had been drawn, on the principle that if the lower in-

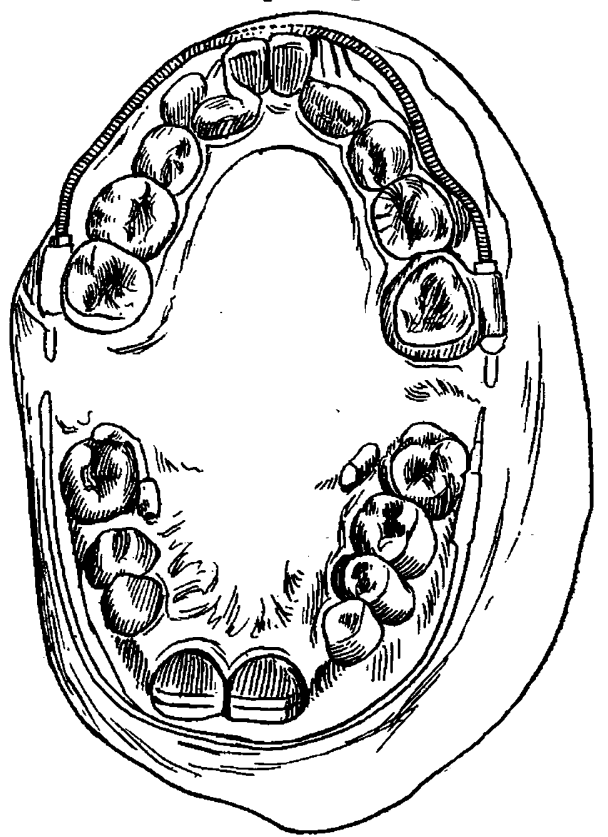

Fig. 2.-John M. Upper fixtures, placed April 19, 1900. Lower fixtures, about May 3 . These fixtures were worn in a trip to Europe, June 6,1900 , and remained in place until his return, Nov. 16 1900

cisors were retained in position the upper ones could not fall back. Nothing was put upon the upper teeth. This wire retainer was broken and repaired from time to time, but was kept in place until January, 1902, thirteen

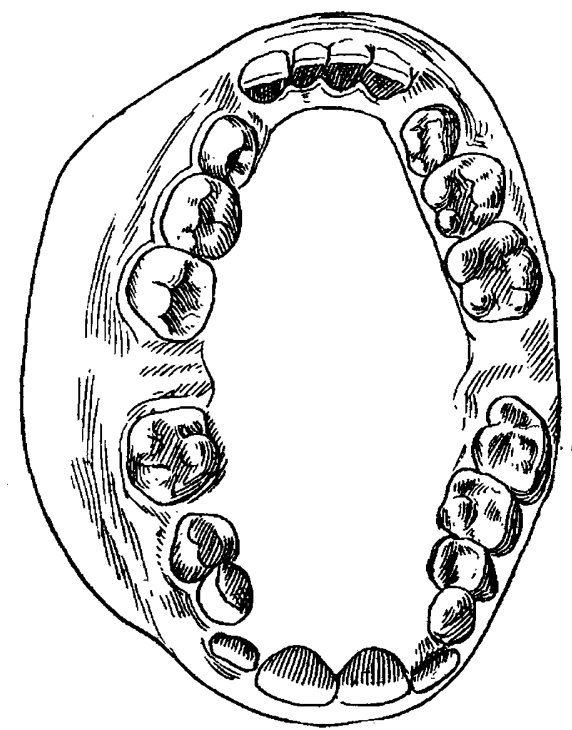

Fig. 3.-John M. Appearance of the teeth Nov. 16, 1900, after his return from an absence of five months and ten days.

months. Within a month from this date, as the bicuspids had begun to appear, rings and bars similar to those put on twenty months before were arranged to complete the expansion of the two arches above and below, and on February 6 and 10 , the bars having been placed, the teeth were tied to them and traction was begun. On February 13 a gold screw was placed in the grinding end of the second left upper bicuspid, which tooth was partly 
erupted. three-quarters of its width inside the arch, as was also the right second bicuspid. This screw was wired to the bar. On March 10, one month from the time the fixtures were reapplied, it was discovered that the upper left permanent molar did not occlude properly with the lower, but that owing to an early loss of the second temnorary molar it had come forward the full width of one cusp. As this occlusion would inevitably produce irreg-

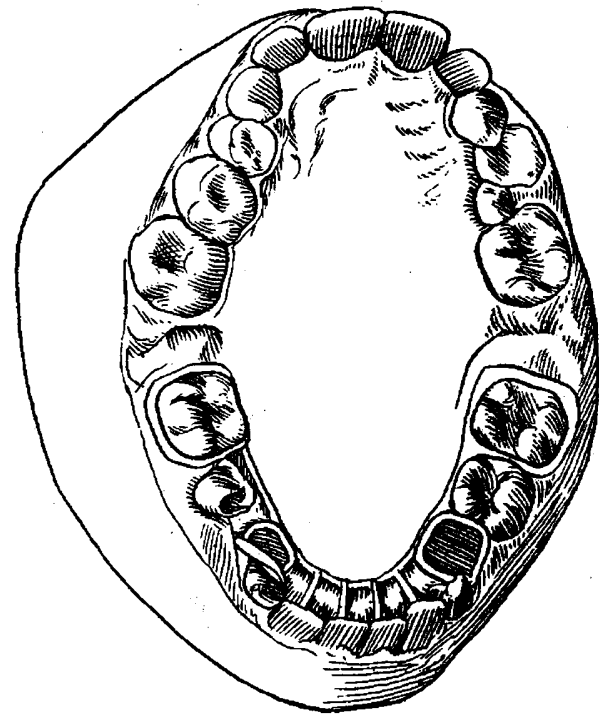

Fig. 4.-John M., December, 1901. Wire retainer modified to throw outward the erupting cuspids as the first temporaly molars have fallen away.

ularity in the occlusion of all the teeth forward of that point, on that side of the jaw, an upper rubber plate was inserted on March 17, 1902, which carried a screw resting in a long socket with a nut (afterwards changed to two nuts) on the screw, a claw on the end of the screw which rested against the upper molar above the line of the ring that was cemented to that molar. This claw

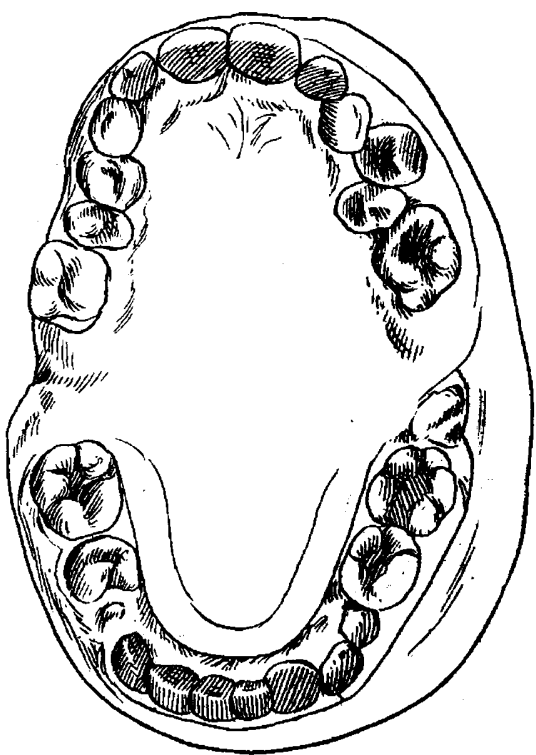

Fig. 5,-John M., January, 1902. Shows condition of teeth after one year of wearing the lower wire retainer only.

prevented the screw from turning in the socket, and the turning of the nuts on the screw exerted a pressure backward against this permanent molar, which pressure was sustained by the entire roof of the mouth, contact against the incisor teeth beneath their rings, and the hold that the plate got under the ring attached to the right upper molar.
Now began the most difficult part of this regulating for the boy. The force of eruption forward was so great that to obtain the slight movement backward that should allow the cusps of the left upper and lower molars

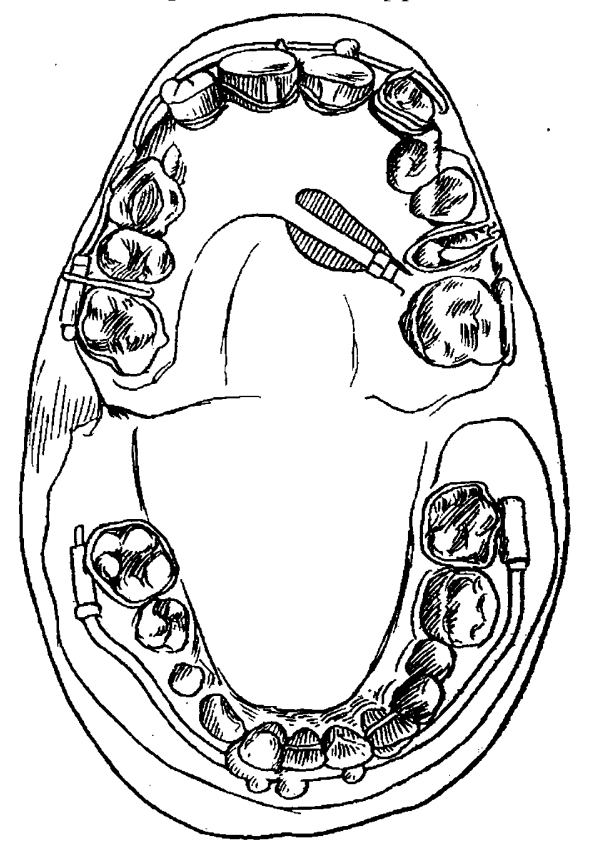

Fig. 6.-John M., March, 1902. Shows progress made in pushing backward the first left upper molar in about forty days, and exhibits fairly well the fixtures employed when he fell ill with measles and was not seen for one month.

to come into their proper places, it was necessary to exert an opposing force that perceptibly changed (at least temporarily) the shape of the roof of the mouth. This pressure moved the rubber plate forward so that the scalloped points that penetrated between the teeth on that side of the mouth were moved to the centers of the

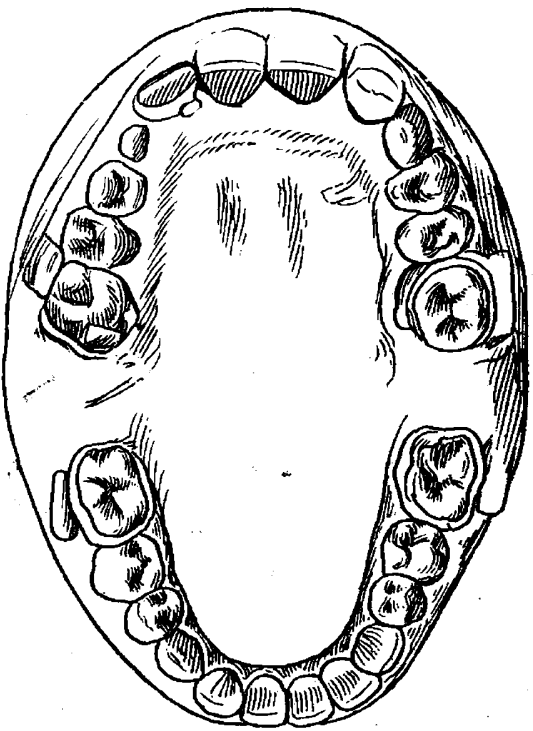

Fig. TA.-John M., May 16, 1902. After recovery from measles. Shows conditions twenty-six days later, with left superlor molar pushed back about $3 / 32$ of an inch and the adjoining bicuspids drawn nearly to their proper position.

teeth, and the four incisors were driven forward nearly one-eighth of an inch.

On March 28 the second upper bicuspids, whose movements were commenced February 13 , were found to be in place, that is, sufficiently drawn outward toward the bar not to require further movement. They were actually a little too far out. At this time measles attacked 
the children, and one month passed before I saw the patients again. During the eleven days that I had been trying to move the left upper molar backward, using only one nut, little progress was made, but on April 28 and 30 I resumed work by placing the two nuts in position and renewed nnemeinns unnn the molar. In fourteen

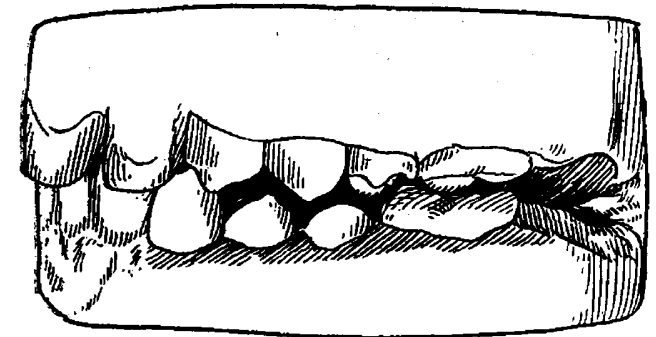

Fig. 7B.-John M., May 16, 1902. Shows side view of teeth with mouth closed.

days the conditions were such as are evidenced by the models. The upper and lower left molars cusped with considerable accuracy, and I made my preparations to let the boy carry this regulating plate in his mouth again across the ocean. Previous to his sailing I constructed two upper rubber suction plates, designed to

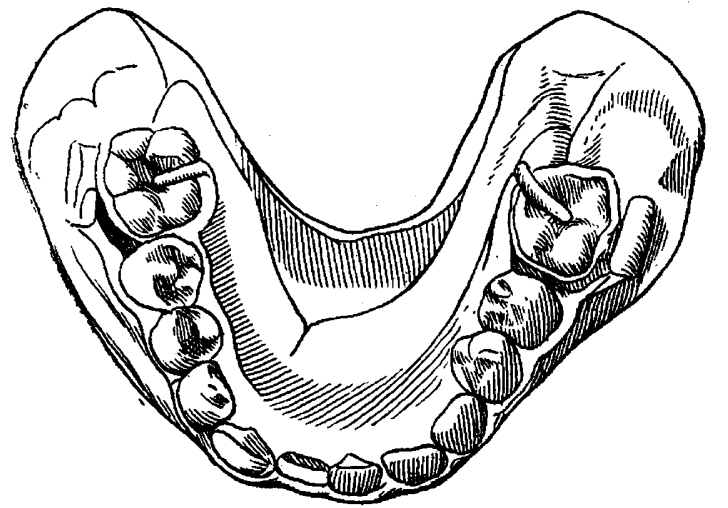

Fig. TC.--John M., May 16, 1902. Shows lower retainer in place the day boy sailed for Europe the second time.

hold the upper molar where it is, to guide the bicuspids as they shall continue to erupt, inclining them a little outward of the lines of the normal arch, and for the time being to prevent the incisors from falling back, although they are now too far out. I have made a lower retaining apparatus that will scarcely more than touch

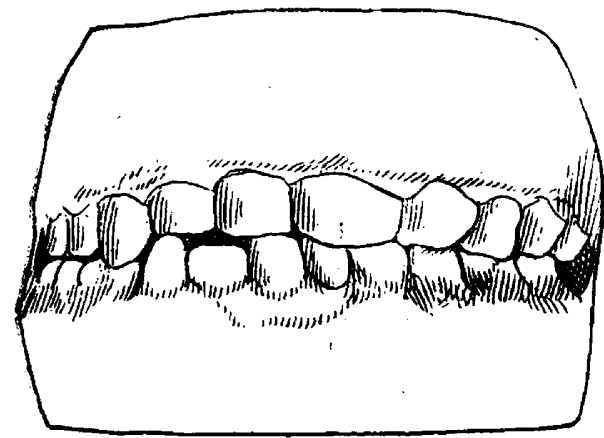

Fig. A.-Louise M., 41/2 years old. Temporary teeth all in place: mouth closed.

the lower teeth at the gum margin, but that snaps in after the daily cleaning, and that will absolutely prevent the dropping back into a smaller arch of any of the teeth that have been drawn forward or outward. As soon, therefore, as the bicuspids shall have developed sufficiently for their long cusps to interlock the upper with the lower, the upper retaining plates may be dis- carded, for this cusping will surely hold the upper teeth in position so long as the lower teeth are firmly held. Having plenty of room, inasmuch as none of these teeth are in contact with each other, the development of the bicuspids was remarkably rapid. The models show how rapid.

The same plan was adopted for the little girl as for her brother, and the enlargement of both arches was ac-

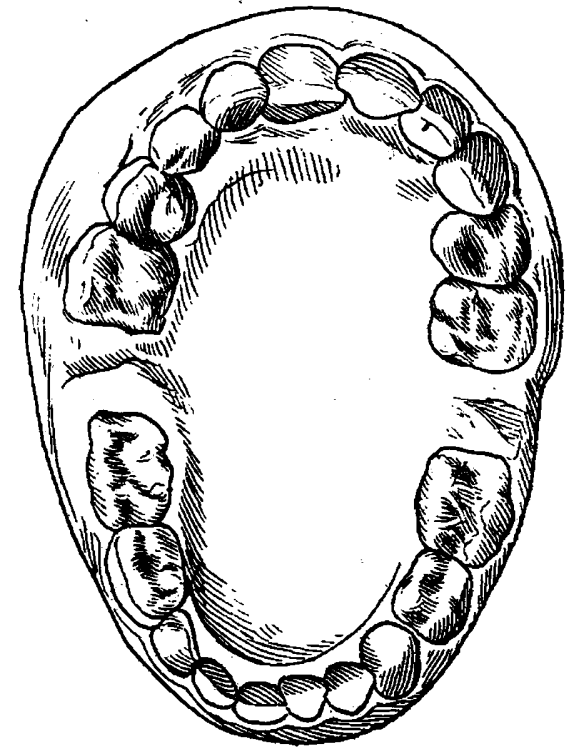

Fig. B.-Louise M. Same mouth and same date. Mouth open.

complished without any complaint of pain on the part of either child.

When the regulating fixtures had remained without disturbance some weeks after they had accomplished. their work a wire retaining plate was adapted to the lower teeth so as to snap into place. This retainer holds the incisors securely forward and in proper relation with the molars. It gives ample room for the development

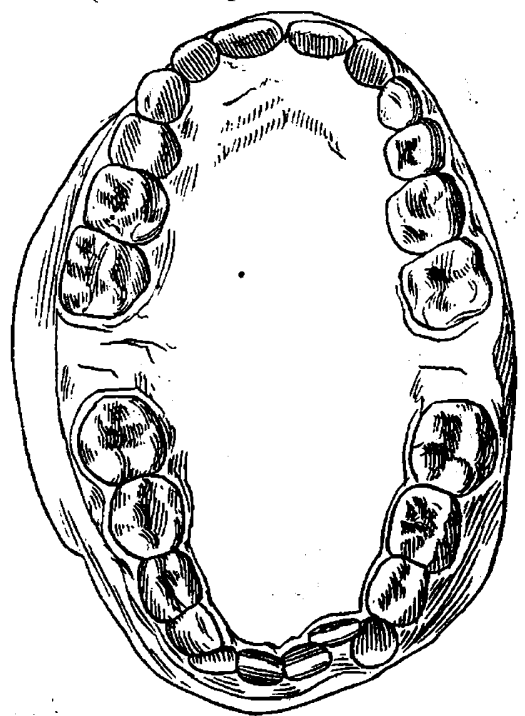

Fig. C.--Loulse M. July, 1897. Same mouth, showing the flrst permanent molars and the incisors partly erupted.

of the lower bicuspids and cuspids, and the upper teeth developing a little later will also have ample room to come, to their respective places because the upper incisors are held forward by shutting over the lower incisors, which are held firmly in position by the retainer.

I wish to emphasize the following facts:

First.: That a perfectly arranged lower arch in ordinary cases guides the teeth of the upper arch into 
their proper positions and holds them there without additional appliances, and even in a case where the temporary teeth are irregular, operations to correct deformity may be begun almost as soon as the first permanent molars and incisors make their appearance.

Second. That these operations may be almost or quite painless.

Third. That they may be accomplished with great

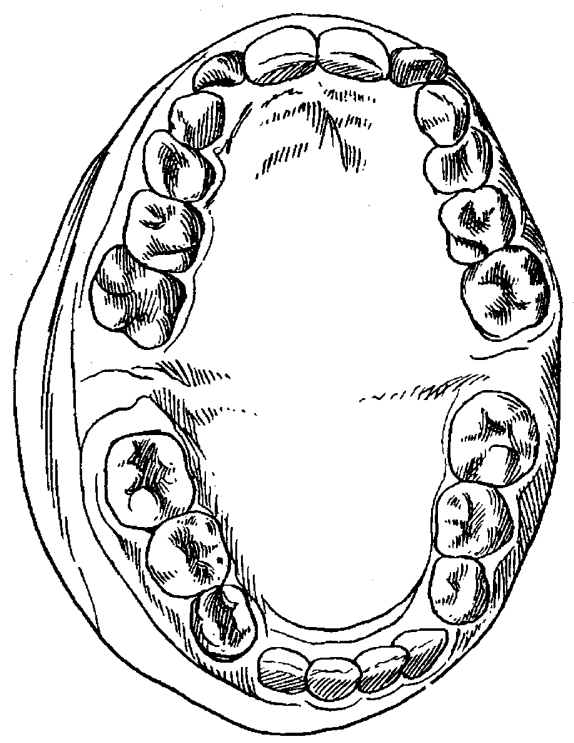

Fig. D.--Louise M., Iecember, 1900. Shows lower incisors drawn Fig. D.--Louise M., Iecember, 1900 . Shows lower incisors drawn
forward considerably and a beginning made on the upper incisors.

rapidity and with such certainty that absence through unexpected sickness or protracted journeyings scarcely interrupts the orderly progress of the work.

Fourth. That this work may be accomplished with no perceptible detriment to the teeth.

Fifth. That the regulating fixtures themselves may

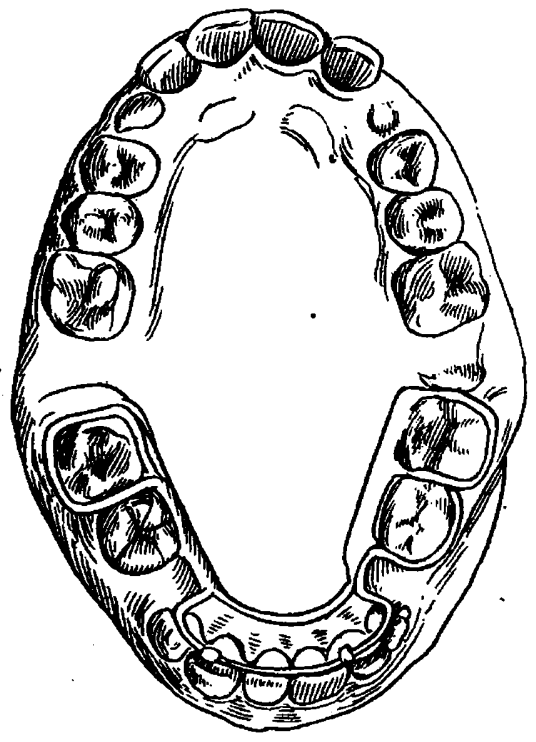

Fig. E.--IJouise M., May 20, 1902. Shows the mouth open, with the inclsors both above and below advanced to their proper places and the Iower retainer in position. No retalner above.

be retained as retainers weeks or months after they have finished their corrective work.

Sixth. That retaining plates may be inserted that retain the lower teeth in position so surely that, as a rule, no retainer is needed above, if we have paid strict attention to the proper occlusion of the teeth.

Seventh. That these retaining fixtures may touch the teeth so slightly, as illustrated by Dr. Baker of Boston, that even if they are worn continuously without removal, the teeth can be as thoroughly cleansed around them as though the retaining fixtures were not in place.

\section{DISCUSSION.}

DR. E. S. TALboT, Chicago-I wish to take exception to the use of the term "contraction." The term has crept into the profession without, knowing the etiology of the conditions represented. There is not a contraction. It is an arrested development. Contraction means a condition in which a jaw has reached a certain size and then has grown smaller. Here and in all of the cases where one jaw is smaller than the other the term is not proper, and is misleading.

There are two objections to the correction of irregularities at this particular time. The roots of the permanent teeth are not properly formed and moving has a tendency to produce deformity of the roots. This has been seen in children who have struck their teeth. The second objection is that when arrest of development takes place it is not known whether that jaw will develop. There may be an arrest of development that never will progress. The arrest may take place in the temporary teeth and not in the permanent. Moving of the teeth is not advisable since they are thrown from the inner surface of the alveolar process and there is little or no bone left on the outer border. Such a case is illustrated in Tomes' work on dental surgery, where teeth erupted on the outer border of the alveolar process. There is an advantage, on the other hand, in assisting naturally in developing the alveolar processes and the jaw-bone.

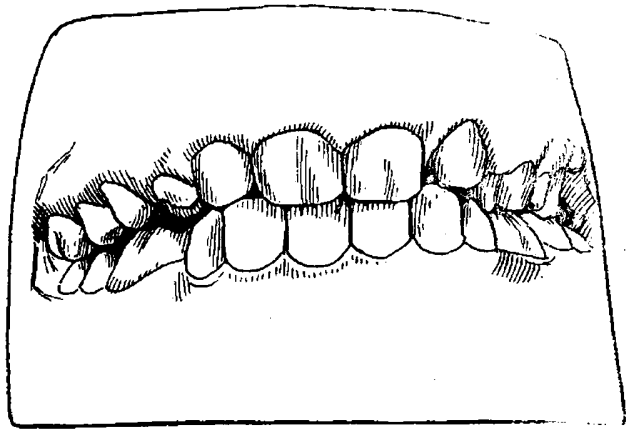

Fig. F.-Louise M., May 20, 1902. Same mouth, with lower re taining fixture in place, but not upper; teeth closed, showing how taining fixture in place, but not upper;
the cusping retains the teeth in position.

I do not think there is a change in the roof of the mouth as mentioned by the writer, but in the alveolar process. Some New York neurologists have made a great mistake in that point. In a paper before one of the societies, the writer spoke of a change in the vault, and there was not a single case reported to show a change. There was rather hypertrophy in the alveolar process, which is very common among neurotics.

The two children operated on are certainly degenerate children. Dr. Bogue has done a fine piece of work, and he has been assisted by the children's going abroad. Had they remained at home the chances are they would not have gotten on so well. They would have broken down. This brings up a point not mentioned in the text-books, that all of these children, who have arrested development of the jaw, are neurotics and degenerates. The presence of the arrest shows that the system is unstable. Whether to commence this work early or at the period of puberty is a difficult question. I venture to say that if Bogue will watch these children he will find that from 12 to 16 years they will be found very irritable and nervous. Such has been my experience.

Dr. Boguf-I would like to ask Dr. Talbot to define what he means by "degenerate."

Dr. Talbor-One whose nervons system is unstable and whose physical development is a departure from the normal.

DR. VIDA A. JАATHAM, Chicago-The work of painless regulation cases is a very, very strong point. To me these cases are the most objectionable for the conditions wear upon the nervous and mental system of both patients and parents. I wias glad to hear the Doctor speak of the second and third nuts. 
The little folks will turn the appliances with their tongue back to the old place. If the second nut controls this I am exceedingly glad to know it.

One question from a developmental point: in a vertical section through the face, the lower jaw shows a more pronounced eruption than the upper, $Y$ wondered if this makes any differ ence in the eruption of the process and in its character as well as in the teeth.

Dr. J. L. WiLliams, Boston-I want to express my approval of this painless process. My habit has heen always to remove the pressure at the first indication of pain. The teeth can be moved intermittently without harm. I have seen mischief resulting when the rubber was not watched. In one case mentioned, after careful correction of the lower teeth, at the urgent solicitation of the patient's mother, the regulation of the upper teeth was commenced, with the provision that the patient should come to me for frequent adjustments. This she neglected to do, and though there was much pain, she thought mind was superior to matter, and when I next saw her the pulp of one of the inciser teeth was dead. The intermittent regulation of teeth is the only safe method.

Dr. Bogue, in closing-I acrept Dr. Talbot's exception very gladly, but will take the liberty of repeating what $I$ did say: "That there was a perceptible change, which lasted temporarily, of the shape of the roof of the mouth." I did not mean that anything but. the gum was really affected. In regulation cases the alternate work and rest is the only way to accomplish results with entire propriety and health. The extraction of teeth to make room is a fallacy never so fully understood by me as to-day, and my understanding of it is after a pretty severe lesson. I have now in my possession upwards of 2000 models of the mouths and ieeth of patients who have passed through my hands, in many of whose cases I have models taken year after year. The changes that take place before extraction and after extraction are thereby before our eyes. These illustrations of the conditions at varying dates have shown me that the Creator knew a great deal more than we do about how to make room; for the cusping of teeth, upper and lower, with each other is an absolutely essential thing if the mastication of our food is to be performed as Nature intended. One of our most eminent orthopedic dental surgeons admitted that the question of occlusion had not been prominent in his mind, that his work had been-up to the period at which he spokesolely for the appearance of the teeth and not necessarily for utility. Starting with the principle that the arch generally needs to be extended and that the cusping of teeth will almost always hold them in place once they have been gotten there, I inferred that it was much ensier to do for a growing child what was required than to wait until that child was more nearly formed, and Dr. Williams' plan of alternate rest and work has always been operative with me whenever such work has been undertaken with children. I have been very much pleased that these children have never even complained of pain.

Dr. Talbot's definition of diegeneracy does not altogether apply to this little chap. I would sometimes address him in German, French or English and he would answer with perfect facility. He is as well versed in lessons as a boy of fourteen. I have never seen his superior in intelligence. I acknowledge that he is nervous and that he is delicate. $\mathrm{He}$ is a boy who seems to be standing in a precarious condition and his mother knows it full well. She, too, is one of the brightest women 1 ever met.

Regarding Dr. Latham's question, I am not able to answer whether the development of the teeth was in the way she mentioned. In this case I am quite sure that the teeth developed after removal of the obstructions with much greater rapidity than before. What the condition of their roots may be, of course, no one knows.

Physicians Advertise-A Lay Opinion.-Concerning the sickness of the King of England, the Christian Advocate remarks: "The papers have fairly swarmed with interviews from physicians, whose code of medical ethics forbids them to advertise."

\section{EL.ECTRIC OZONATION IN NEURALGIA.* G. LENOX CURTIS, M.D. \\ CONSULTANT TO THE RED CROSS HOSPITAL. NEW YORK CITY.}

The term neuralgia may be applied to all pains found in animal tissue that may be regarded as being nearly or quite in a perfect physical condition, especially if the pains have become chronic. To designate the locality of the cause of pain, which may or may not be in the region of pain, and leaving out what may be regarded as functional disturbance, we may mention, for illust ation of my subject, facial neuralgia, gastralgia. myalgia, as of the pain in myelitis and pyelitis, all of which are only different phases of disturbances called neuralgia. The locality of the keenest pains may be in the parts suggested by those names or they may be at greater or less distance. Neuralgia in and about the face and mouth is generally easily determined, but there are cases where there seem to be complications.

Other forms of pain, such as gout, rheumatism, sciatica and lumbago may all come under the general terms of affections of the nerves and may all be treated in connection. But this would open a wider field than I desire to discuss at this time.

The pain about a tooth in one jaw may cause pain in the opposite jaw. It is well known that a defective lower side tooth often causes pain in the upper tooth. But it may be said that in cases of pulpitis, gingivitis, periostitis and pericementitis, the pains are found in the parts involved.

As these latter forms of neuralgia are probably the ones that will most interest this section of medicine. I will confine my remarks mainly to them. My aim is to call the attention to the power of electric ozonation; its effect upon this disease I regard as a comparatively new phase of practice in medicine.

EXPLANATION OF THE REMEDIAL ACTION.

After three years of experimental work, I called the attention of the medical profession, in October, 1901, to it in a paper read before the Academy of Medicine in New York. ${ }^{1}$ In that paper the plan by which ozone may be properly made, and at the same time enable the practitioner to force it directly into and through the affected parts, was clearly set forth. I also explained its effects and gave report of cases in which the stimulating and ozonizing speedily re-established the normal functions. When nerve force and proper nutrition are established and equilibrium is re-established a high condition of health is the result. I do not wish to be understood as saying that by electric ozonation a normal physical condition can be re-established in a diseased organ, such as follows the loss of tubules in chronic nephritis, abscesses of the lungs and liver. or a cicatrix in a nerve trunk following a traumatic lesion or calcaric deposit in the pulp of a tooth. But I do imply that by electric ozonation nerve force and circulation can be sufficiently re-established in the parts, to lead to health and the parts be left in the best condition possible under the circumstances.

$$
\text { METHOD OF APPLICATION. }
$$

The mechanism that will make this remarkable element is a system of coils of fine wire, so arranged as to change the quality of the current of electricity, from the street, into the wonderful therapeutic agent.

One of the changes in the electric current effected by passing through the machine is increase of voltage, while

* Read at the Fifty-third Annual Meeting of the American Medical Association, in the Section on Stomatology, and approved for publication by the Executive Committee: Drs. G. V. I. Brown, M. H. Fletcher and R. R. Andrews.

1. N. Y. Med. Jour., Jan. 18-Feb. 1, 1902 